2. Ortonne JP, Bose SK. Vitiligo: where do we stand? Pigment Cell Res. 1993;6:61-72.

3. Ucak $\mathrm{H}$, Soylu $\mathrm{E}$, Ozturk $\mathrm{S}$, et al. Audiological abnormalities in patients with alopecia areata. J Eur Acad Dermatol Venereol. 2014;28:1045-1048.

4. Shaheen MA, Matta M, Rahman TTA, Refaat N. Hearing threshold abnormalities in patients with alopecia areata. Egypt J Otolaryngol. 2015;31:267-272.

5. Marcus DC, Wu T, Wangemann P, Kofuji P. KCNJ10 (Kir4.1) potassium channel knockout abolishes endocochlear potential. Am J Physiol Cell Physiol. 2002;282:C403-C407.

6. Takeda K, Takahashi NH, Shibahara S. Neuroendocrine functions of melanocytes: beyond the skin-deep melanin maker. Tohoku J Exp Med. 2007;211:201-221.
7. Zhang W, Dai M, Fridberger A, et al. Perivascular-resident macrophage-like melanocytes in the inner ear are essential for the integrity of the intrastrial fluid-blood barrier. Proc Natl Acad Sci USA. 2012;109:10388-10393.

8. Heaton JM, Mills RP. Sensorineural hearing loss associated with birdshot retinochoroidopathy. Arch Otolaryngol Head Neck Surg. 1993;119:680-681.

9. Akay BN, Bozkir M, Anadolu Y, Gullu S. Epidemiology of vitiligo, associated autoimmune diseases and audiological abnormalities: Ankara study of 80 patients in Turkey. J Eur Acad Dermatol Venereol. 2010;24:1144-1150.

10. Angrisani RM, Azevedo MF, Pereira LD, Lopes C, Garcia MV. A study on otoacoustic emissions and suppression effects in patients with vitiligo. Braz J Otorhinolaryngol. 2009;75:111-115.

\title{
A new endoscopic technique to close big nasal septal perforations: Prospective evaluation of the double meat hook technique in 19 consecutive cases
}

\section{1 | INTRODUCTION}

A nasal septum perforation is a defect in three distinct contiguous layers, composed of both right and left septal mucoperichondrial flaps and the intermediate cartilage. ${ }^{1}$ The interruption of the structural integrity of the septum disrupts lamellar nasal airflow. Subsequently, patients can present with a spectrum of complaints such as nasal obstruction, crusting, recurrent epistaxis, Saddle nose deformities and whistling.

A septum perforation never closes spontaneously. Management of symptomatic patients initially has to be conservative with regular nasal irrigation and emollients. ${ }^{2}$ A silicone septal obturator is an alternative conservative option but this non-physiological device can cause irritation and nasal obstruction. When conservative treatment is not helpful, there is a definite indication for surgical treatment. $^{3,4}$

Surgical treatment involves either closure or enlargement of the perforation. The latter technique is not popular. Surgical repair of big septum perforations (defined as a diameter of 2 to 4 centimetres) is a challenging procedure, which is reflected by a modest success range of $30 \%$ to $70 \%$ reported in the literature. ${ }^{2-6}$ Presently, no single surgical closure technique is considered a gold standard. The majority of surgeons prefer a three-layer repair with tension-free closure of both mucoperichondrial flaps and interposition of an autologous graft.

The technique described in this study is different from existing techniques to close a big septum perforation. The technique is endoscopically guided and based exclusively on the use of extended mucosal flaps from the nose, elevated through a new type of incision called the double meat hook. The perforation is closed margin-to-margin and tension-free without the need for deeper mucosal incisions as seen in rotation and advancement flaps. The technique hereby delivers a physiological end result with minor morbidity.

\section{2 | METHODS}

\subsection{Ethical considerations}

All patients provided informed consent before commencing treatment, and information was stored in a secure location with anonymous evaluation of results.

\subsection{Patient characteristics}

Between 2010 and 2015, 19 consecutive patients with a big symptomatic septum perforation were treated with the double meat hook technique by the first author of this study (HD). Patients were followed for at least 1 year. The majority of patients were male $(\mathrm{N}=12 ; 63.2 \%)$ with a mean age of 51.5 years (range 26-77). Causes for the perforations were as follows: cocaine abuse $(N=8$; $42.1 \%$ ), idiopathic ( $N=6 ; 31.6 \%)$, post-septum correction $(N=4$; $21.0 \%)$ and post-traumatic $(\mathrm{N}=1 ; 5.3 \%)$ (Table 1). 
The size of the perforation was measured in two dimensions using an extra fine blunt tip probe. For anterior to posterior diameter measurement, the probe was marked with the tip placed against the posterior border of the perforation and marked again with the tip placed at the anterior border. The distance between the two markings gave an accurate measurement of the perforation diameter. A second diameter was measured from the posterior-superior border to anterior-inferior border. A perforation diameter between 2 and 4 centimetre was considered a big perforation.

\section{3 | Surgical technique}

Tension-free closure of a big septum perforation is surgically challenging because the amount of mucosa in the nasal cavity is limited. The lining of the nasal floor, the lateral nasal wall and medial and lateral surface of the inferior turbinate bone are valuable donor site extensions. The double meat hook incision provides access to these donor sites, and endoscopic view facilitates excellent control of mucosal flap elevation and suturing.

The procedure starts with a full transfixion incision which is extended onto the nasal floor and the lateral nasal, up until the insertion of the inferior turbinate. The shape of this incision looks like a meat hook (Figure 1A).

Under endoscopic view, mucoperichondrial flaps are elevated anterior, caudal, cranial and posterior to the septum perforation. Flap elevation is extended to the nasal floor and lateral nasal wall in a subperiostial plane. In some cases, this flap extension is

\section{Keypoints}

- Despite the variety of surgical techniques available to close big symptomatic septum perforations, closure rates of $30 \%$ to $70 \%$ indicate the difficulty of obtaining a good end result.

- The double meat hook technique is a new endoscopically assisted technique that delivers excellent visualisation and control of mucosal flap elevation, extension and suturing.

- Mucosa from the nasal floor, lateral nasal wall and inferior turbinate bone are valuable donor site extensions.

- There is no need for additional incisions into the nasal septal mucosa to perform a tension-free closure. Preservation of the structural integrity and blood supply of the mucosal flaps possibly contributes to a high closure rate and delivers a physiological result.

sufficient to perform a tension-free, margin-to-margin closure. If not, flap elevation is continued to the lateral and medial surface of the inferior turbinate bone. There, the attachment of the lacrimal duct into the mucous membrane of the inferior meatus should be noted (Figure 1B). In most cases, this attachment is flexible and obviates the need to release the duct.

TABLE 1 Demographic data and septal perforation characteristics of the cohort $(N=19)$

\begin{tabular}{|c|c|c|c|c|c|c|c|}
\hline Patient & Age & $\begin{array}{l}\text { Gender } \\
(\mathrm{M} / \mathrm{F})\end{array}$ & $\begin{array}{l}\text { Cause of } \\
\text { perforation }\end{array}$ & $\begin{array}{l}\text { Size }(\mathrm{mm}) / \text { site of } \\
\text { perforation }\end{array}$ & Symptoms & $\begin{array}{l}\text { Result after } \\
1^{\text {st }} \text { operation }\end{array}$ & $\begin{array}{l}\text { Result after } \\
2^{\text {nd }} \text { operation }\end{array}$ \\
\hline 1 & 72 & M & Idiopathic & $23 \times 25$ anterior & Obstruction, crusting & Closed & \\
\hline 3 & 47 & M & Cocaine & $25 \times 27$ anterior & Obstruction, crusting, epistaxis & Closed & \\
\hline 4 & 30 & M & Idiopathic & $22 \times 22$ anterior & Obstruction,crusting & Closed & \\
\hline 7 & 39 & $\mathrm{~F}$ & Cocaine & $20 \times 20$ anterior & Obstruction, rhinorrhoea & Closed & \\
\hline 8 & 41 & $\mathrm{~F}$ & Trauma & $30 \times 30$ anterior & Obstruction, saddle nose & Open & Closed \\
\hline 9 & 53 & M & Surgery & $25 \times 25$ anterior & Obstruction, epistaxis & Closed & \\
\hline 10 & 60 & $\mathrm{~F}$ & Cocaine & $40 \times 40$ anterior & Obstruction, drooping tip, epistaxis, crusting & Closed & \\
\hline 14 & 34 & $\mathrm{~F}$ & Cocaine & $22 \times 22$ anterior & Obstruction, crusting & Open & Open $(5 \times 5 \mathrm{~mm})$ \\
\hline 15 & 45 & M & Cocaine & $20 \times 20$ anterior & Obstruction, crusting, epistaxis & Open & Open $(5 \times 5 \mathrm{~mm})$ \\
\hline 16 & 46 & M & Idiopathic & $32 \times 32$ anterior & Obstruction, crusting & Open & Closed \\
\hline 17 & 46 & M & Surgery & $20 \times 20$ anterior & Obstruction, crusting & Closed & \\
\hline 18 & 77 & M & Idiopathic & $22 \times 22$ anterior & Epistaxis, irritation & Closed & \\
\hline 19 & 36 & $\mathrm{~F}$ & Idiopathic & $20 \times 20$ anterior & Obstruction, crusting & Closed & \\
\hline
\end{tabular}

$M$, male; $F$, female; $m$, millimetres. 

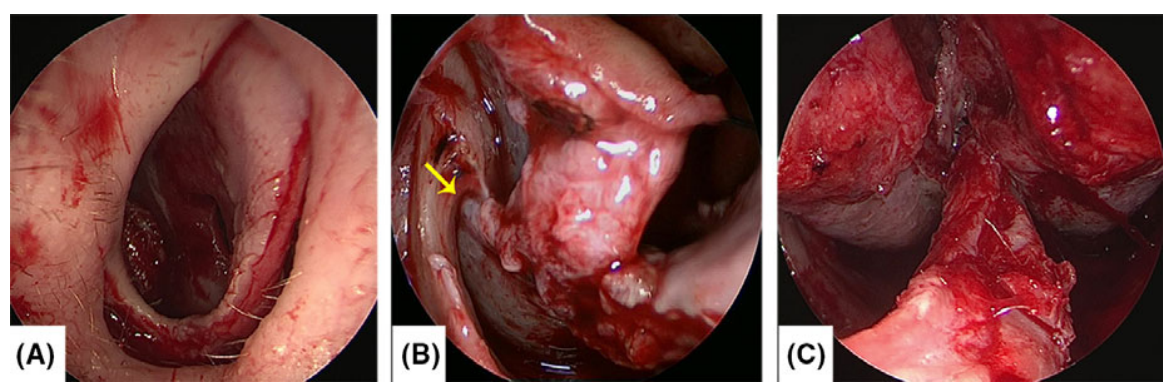

FIGURE 1 A, Right nasal cavity: a full transfixion incision anterior to the caudal border of the septum is extended to the nasal floor and lateral nasal wall, up to the insertion of the inferior turbinate. The shape of the incision looks like a "meat hook." B, Right nasal cavity: the mucoperichondrial flap is extended to the nasal floor and lateral nasal wall and lateral and medial side of the inferior turbinate bone, providing extra length for tension-free closure. Note that the insertion of the lacrimal duct (yellow arrow) is mobilized. It can be cut or left in place, according to the need for flap mobilisation. C, Endoscopic view of a repaired defect, showing an interposition cartilage graft and bilateral dead space after elevation of extended mucosal flaps on both sides

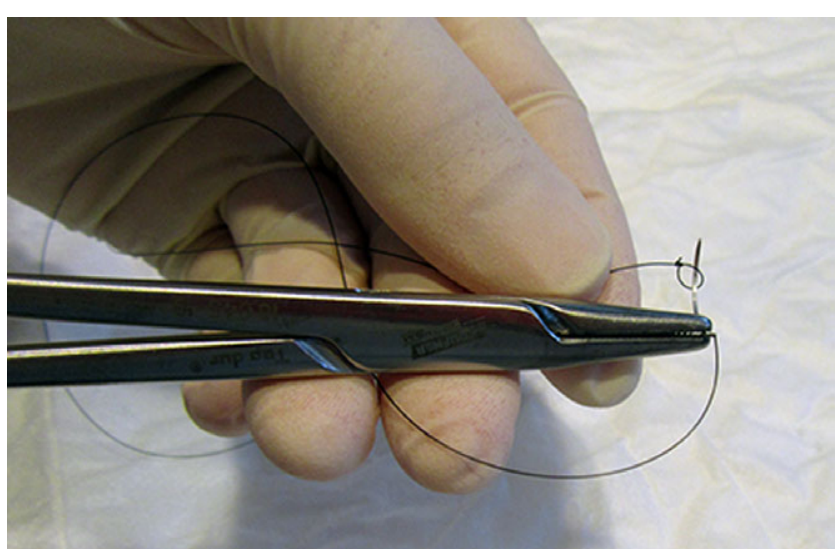

FIGURE 2 A 5/0 Prolene knot, tied over a suction tube to provide a loop to which the first pass of the suture lock's. Then, running (posterior to anterior) suturing provides a tight margin-tomargin closure

After the flaps are mobilised, the next step is to create a tensionfree, margin-to-margin closure of the perforation. For this purpose, a $5 / 0$ prolene suture in continuous fashion is used. First a knotted loop is made at the end of the thread. Then, the needle is inserted after its first pass through the mucosa at the most posterior part of the perforation (Figure 2). Then, it becomes possible to perform posterior to anterior continuous suturing until the defect is closed.

After closing the perforation, it is advisable to place an interposition graft between the repaired mucous membrane. The interposition graft can be either residual crushed septum cartilage, perpendicular plate bone, conchal cartilage or (homologous) temporalis fascia. To support and protect the repaired septum, a silicone splint is placed on both sides of the septum and fixed with 4/0 ethilon mattress sutures. The splints are removed after 6 weeks. A light nasal dressing is placed in the internal nasal valve area and removed by the patient after 24 hours.

Elevation of mucosa from the nasal floor and lateral nasal wall results in a large dead space between the bone and raised mucosal flaps (Figure 1C). This dead space gradually resolves by itself within the first 6 weeks following surgery (Figure 3 and Table 2).To prevent bleeding from the dead space area, it is filled with Surgicel ${ }^{\circledR}$ (Johnson \& Johnson Medical Ltd., Wokingham, UK).

\section{3 | RESULTS}

Regular post-operative visits were performed at 2 weeks, 6 weeks and 6 and 12 months following surgery. Results and sequential findings are shown in Tables 1 and 2. Thirteen perforations (68.5\%) remained closed after one operation. In case of a persistent perforation, revision surgery was performed within 4 months. Three perforations remained closed after revision resulting in an overall success rate of $84.2 \%$. The three persistent perforations did reduce in size ( $2 \mathrm{~cm}$ to $1 \mathrm{~cm}, 2 \mathrm{~cm}$ to $5 \mathrm{~mm}$ and $2,5 \mathrm{~cm}$ to $5 \mathrm{~mm}$ ) and patients reported sufficient improvement of crusting, epistaxis and nasal obstruction to avoid further treatment. Two patients with a closed
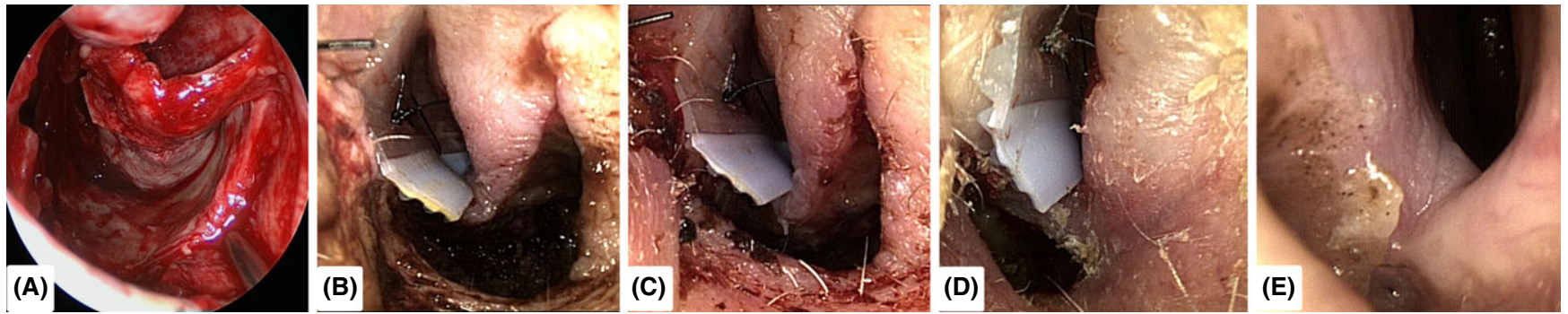

FIGURE 3 Left nasal cavity: the dead space between bony nasal floor and elevated mucosal flap resolves gradually A, endoscopic view of bilateral dead space immediate after perforation closure; B, 2 days post-operative; C, 5 days post-operative; D, 2 weeks post-operative; E, 6 weeks post-operative after splint removal) 
TABLE 2 Overview of relevant findings during consecutive postoperative visits $(N=19)$

\begin{tabular}{|c|c|c|c|c|}
\hline & 5 days & 2 weeks & 6 weeks & 6 months \\
\hline Nasal floor & $\begin{array}{l}\text { - Big dead space filled with } \\
\text { debris } \mathrm{N}=1 \text { (no Surgicel used) } \\
\text { - Big dead space filled with } \\
\text { blood clots } \mathrm{N}=1 \\
\text { (no Surgicel used) } \\
\text { - Big dead space filled with } \\
\text { Surgicel } \mathrm{N}=17\end{array}$ & $\begin{array}{l}\text { - Large dead space filled with } \\
\text { granulation tissue } \mathrm{N}=3 \\
\text { - Small dead space filled with } \\
\text { granulation tissue } \\
\mathrm{N}=6 \\
\text { - Almost lined/some granulation } \\
\text { tissue } \mathrm{N}=10\end{array}$ & $\begin{array}{l}\text { - Lined/scar hypertrophy } \\
\mathrm{N}=4 \\
\text { - Lined/clean scar } \mathrm{N}=4 \\
\text { - Lined/scar with } \\
\text { granulation and/or } \\
\text { slightwound crusting } \\
\mathrm{N}=11\end{array}$ & $\begin{array}{l}\text { - } \text { Normal scar } \mathrm{N}=17 \\
\text { Obvious wound scar } \\
\text { hypertrophy } \mathrm{N}=2\end{array}$ \\
\hline
\end{tabular}

perforation complained of unilateral nasal obstruction, which was present prior to surgery and related to a narrow internal nasal valve. Both patients have been treated successfully with spreader grafts from concha cartilage in a later stage.

\section{4 | DISCUSSION}

Traditionally, most surgeons prefer "open techniques" such as an external rhinoplasty or midfacial degloving approach to expose and reconstruct a large septum perforation. ${ }^{7,8}$ The past decade, more attention is directed towards "closed, endoscopically assisted techniques" in order to avoid external incisions and to reduce donor site morbidity. ${ }^{9}$ Using either a closed or open technique to repair large symptomatic septum perforations, failure rates of $70 \%$ to $30 \%$ illustrate the difficulty of obtaining a good end result. The absence of studies describing a large patient population and the heterogeneity of surgical techniques, population characteristics and methodological design makes it difficult to provide an evidence-based recommendation about the value of each particular surgical technique.

In search to improve septum perforation closure rates and to reduce postoperative morbidity, the double meat hook technique was developed. The double meat hook technique was named after the shape of the incision used. This anteriorly placed incision allows the surgeon to dissect mucosa from the nasal floor and the lateral nasal wall including the mucosal lining of the inferior turbinate bone. These anatomical locations are valuable donor site extensions and provide sufficient mucosa to elevate and to perform a tension-free, margin-to-margin closure. There is no need to further extend the incision into the nasal septal mucosa, as needed for example in rotation and advancement flaps. The double meat hook technique hereby preserves the structural integrity and blood supply of the nasal mucosa, potentially contributing to a high closure rates and a more physiological end result (eg minimal postoperative crusting and open and clean nasal cavities).

Based on the prospective evaluation of 19 consecutive cases with a big septum perforation, we report a closure rate of $68.5 \%$ after one operation and $84.2 \%$ after one revision performed within 4 months. This result is comparable with earlier publications, and perhaps best compared to the study of Giacomini et al. who described complete closure of 10 of 14 big septum perforations, treated endoscopically with bipedicled-bilateral mucoperichiondrial flaps and auricular interposition grafts. ${ }^{9}$

Special attention is directed towards the substantial residual dead space between the nasal floor and elevated mucosa. Intuitively this defect seems problematic if left untreated. However, as shown in Figure 3 and Table 2, the dead space gradually resolves over time. In most cases, the nasal floor was properly covered after 2 weeks. Post-operative bleeding from the dead space was reported in one of our first patients. Since then, this adverse event is avoided by filling the dead space with Surgicel.

Based on our results, we feel confident to advise the consideration of the double meat hook technique to close a septum perforation 2 to $4 \mathrm{~cm}$ in size.

\section{CONFLICT OF INTEREST}

The authors have nothing to disclose.

\section{ORCID}

F.R. Datema iD http://orcid.org/0000-0002-8020-1739

H. Dixon F.R. Datema iD

Department of Otolaryngology/Head and Neck Surgery, Erasmus Medical Center, Rotterdam, Zuid-Holland, The Netherland 
Correspondence

F.R. Datema, Department of Otolaryngology/Head and Neck Surgery, Erasmus Medical Center, Rotterdam, Zuid-Holland, The Netherland.

Email: f.datema@erasmusmc.nl

\section{REFERENCES}

1. Kridel RWH. Considerations in the etiology, treatment, and repair of septal perforations. Facial Plast Surg Clin North Am. 2004;12:435450.

2. Moon IJ, Kim SW, Han DH, et al. Predictive factors for the outcome of septal perforation repair. Auris Nasus Larynx. 2011;38:5257.

3. Cogswell LK, Goodacre TE. The management of nasoseptal perforation. Br J Plast Surg. 2000;53:117-120.
4. Shikowitz MJ. Vascularized mucoperiosteal pull through flap for closure of large septal perforation. Laryngoscope. 2007;117:750-755.

5. Woolford TJ, Jones NS. Repair of nasal septal perforations using local mucosal flaps and a composite cartilage graft. J Laryngol Otol. 2001;115:22-25.

6. Goodman WS, Strelkzow VV. The Surgical closure of nasoseptal perforations. Laryngoscope. 1982;92:121-124.

7. Kridel RW, Appling WD, Wright WK. Septal perforation closure utilizing the external septorhinoplasty approach. Arch Otolaryngol Head Neck Surg. 1986;112:168-172.

8. Arnstein DP, Berke GS. Surgical considerations in the open rhinoplasty approach to closure of septal perforations. Arch Otolaryngol Head Neck Surg. 1989;115:435-438.

9. Giacomini PG, Ferraro S, Girolamo S, et al. Large nasal septal perforation repair by close endoscopically assisted approach.Ann Plast Surg. 2011:66:633-636.

\section{External validation of a cancer risk prediction model for suspected head and neck cancer referrals}

\section{1 | INTRODUCTION}

Head and neck cancer (HNC) affects more than 9000 new patients every year in England and Wales with an additional 1200 in Scotland. $^{1,2}$ Patients are urgently referred to head and neck clinics for further assessment when a suspicion of cancer is raised in the primary care setting. In England, the referral criteria are based on the NICE recommendations for symptoms associated with $\mathrm{HNC}^{2}$ A different combination of symptoms is described in the Scottish cancer referral guidelines. ${ }^{3}$ There is currently no unified referral pro forma across the different UK cancer networks.

The current guidelines have been refined several times over the past two decades. The aim was to improve the detection rate of HNC, expedite patients' journey from the first attendance in general practice (GP) to the specialist clinic and commence appropriate treatment based on diagnosis. ${ }^{4}$ Nevertheless, a high number of inappropriate referrals have been reported. This has led to a low HNC detection rate and heavily overbooked clinics. The current recommendations for referral are consensus-based, and thus of low-level evidence. $^{5}$

To refine the referral guidelines, a retrospective cohort study was undertaken to examine the symptoms related to HNC. A risk calculator was generated from this study using a combination of symptoms that had a statistically significant higher predictive value when compared to the NICE recommendations. ${ }^{6}$ The list of significant symptoms is presented in Table 1 . The suggested combination of symptoms has a good predictive power, but the risk calculator has not yet been externally validated. The aim of this study was to validate the HNC risk calculator using a Scottish cohort of patients urgently referred with suspected HNC.

\section{MATERIALS AND METHODS}

This was a retrospective study conducted at the ENT department of Greater Glasgow and Clyde NHS Health Board. All patients referred and seen with an urgent suspicion of HNC between June 2015 and May 2016 were included in the study. Information was collected on patients' demographics, presenting symptoms and diagnosis. Caldicott Guardian approval was obtained from the hospital's governance department prior to data collection.

Head and neck cancer probability for each individual patient was calculated using the symptoms on the published HNC risk calculator. Patient's age and gender were also significant predictors of HNC and were included in the calculator matrix. ${ }^{6}$ The sensitivity, specificity and c-statistic of the calculator based on the Scottish cohort of patients are presented and compared to the previously published data set. The same probability cut-off was applied, set at $0.08 .{ }^{6}$ Chisquare test and independent $t$ test were performed for univariate assessment of association for categorical and continuous variables, respectively. The statistical analysis was performed using the IBM SPSS Version 20.0. Armonk, NY: IBM Corp. 